\title{
Laser-induced corneal cross-linking upon photorefractive ablation with riboflavin
}

\author{
This article was published in the following Dove Press journal: \\ Clinical Ophthalmology \\ I April 2016 \\ Number of times this article has been viewed
}

\author{
Igor M Kornilovskiy' \\ Elmar M Kasimov ${ }^{2}$ \\ Ayten I Sultanova ${ }^{2}$ \\ Alexander A Burtsev' \\ 'Department of Eye Diseases, Federal \\ State Budgetary Institution "National \\ Pirogov Medical Surgical Centre", \\ Ministry of Health, Moscow, Russia; \\ ${ }^{2}$ Department of Eye Diseases, Zarifa \\ Aliyeva National Ophthalmology \\ Center, Ministry of Health, Baku, \\ Azerbaijan
}

Aim: To estimate the biomechanical effect of the laser-induced cross-linking resulting from photorefractive ablation of the cornea with riboflavin.

Methods: Excimer laser ablation studies were performed ex vivo (32 eyes of 16 rabbits) by phototherapeutic keratectomy (PTK) and in vivo (24 eyes of 12 rabbits) by transepithelial photorefractive keratectomy (TransPRK), with and without riboflavin saturation of the stroma. Then, we performed corneal optical coherence tomography on 36 eyes of 18 patients with varying degrees of myopia at different times after the TransPRK was performed with riboflavin saturation of the stroma.

Results: Biomechanical testing of corneal samples saturated with riboflavin revealed cross-linking effect accompanied by the increase in tensile strength and maximum strength. PTK showed increase in tensile strength from $5.1 \pm 1.4$ to $7.2 \pm 1.6 \mathrm{MPa}(P=0.001)$, while TransPRK showed increase in tensile strength from $8.8 \pm 0.9$ to $12.8 \pm 1.3 \mathrm{MPa}(P=0.0004)$. Maximum strength increased from $8.7 \pm 2.5$ to $12.0 \pm 2.8 \mathrm{~N}(P=0.005)$ in PTK and from $12.8 \pm 1.6$ to $18.3 \pm 1.2$ $\mathrm{N}(P=0.0004)$ in TransPRK. Clinical optical coherence tomography studies of the biomicroscopic transparent cornea at different times after TransPRK showed increased density in the surface layers of the stroma and membrane-like structure beneath the epithelium.

Conclusion: Photorefractive ablation of the preliminary corneal stroma saturation with riboflavin causes the effect of laser-induced cross-linking, which is attended with an increase in corneal tensile strength, maximum strength, increased density in the surface layers of the stroma, and formation of a membrane-like structure beneath the epithelium after TransPRK.

Keywords: corneal cross-linking, photorefractive ablation of cornea, riboflavin

\section{Introduction}

Most keratorefractive corneal surgeries are accompanied by the weakening of their biomechanical properties, which in some cases can lead to induced corneal ectasia. Refractive surgeons encountered such a complication when performing excimer laser keratomileusis. ${ }^{1-3}$ According to available published data for a given surgery in dependence on the thickness of the flap, its formation alone is accompanied by the weakening of strength characteristics of the cornea by $20 \%-30 \%$. This attenuation increases with an increase in photorefractive ablation volume. Despite the proposition of the technology combining corneal cross-linking with photorefractive surgeries, such kinds of procedures have not yet been widely adopted in clinical practice. This is due to a number of unwanted side effects related to the additional exposure of the cornea to ultraviolet (UV) radiation upon cross-linking. ${ }^{3-5}$ However, it is the application of riboflavin for corneal collagen cross-linking that predetermined the possibility of applying such a technology for strengthening the cornea in case of corneal ectasia of various etiology. This is because riboflavin not only forms oxy compounds and additional cross-links
Correspondence: Igor M Kornilovskiy Department of Eye Diseases, Federal State Budgetary Institution "National Pirogov Medical Surgical Centre", Nizhnyaya Pervomayskaya 65, 105203 Moscow, Russia Email kornilovsky5ı@yandex.ru
Clinical Ophthalmology 2016:10 587-592

587

Dovepress

http://dx.doi.org/10.2147/OPTH.S101632 (c) (7) () 2016 Kornilovskiy et al. This work is published and licensed by Dove Medical Press Limited. The full terms of this license are available at https://www.dovepress.com/terms.php cc. hereby accept the Terms. Non-commercial uses of the work are permitted without any further permission from Dove Medical Press Limited, provided the work is properly attributed. For permission for commercial use of this work, please see paragraphs 4.2 and 5 of our Terms (https://www.dovepress.com/terms.php). 
in the collagen structure of the stroma upon UV-emission absorption but also has antioxidant properties.

\section{Materials and methods}

Clinical studies were carried out after obtaining written informed consent from the patients and in full conformity with the international and Russian legislation on legal and ethical principles of biomedical research on humans, specified in HAC1 bulletin (On biomedical human research procedure). All animal-handling procedures were performed according to the Guide for the Care and Use of Laboratory Animals of the National Institutes of Health and followed the guidelines of the Animal Welfare Act. All animal experiments were approved by the Ethical Committee of Postgraduate Medical Institute "National Pirogov Medical Surgical Centre", Ministry of Health, Moscow, Russian Federation. Experimental studies were performed on 56 eyes of 28 rabbits. Upon arrival, all animals were housed in individual cages suspended above ground corncob bedding. All animals were housed throughout the acclimation period and during the study in an environmentally controlled room. The room temperature control was set to maintain environmental conditions of $19 \pm 3^{\circ} \mathrm{C}$. The animal house was kept on a $12 \mathrm{~h}$ light/dark cycle. Ex vivo experiments were performed after mechanical epithelial debridement on 32 enucleated eyes of 16 rabbits by $100 \mu \mathrm{m}$ depth excimer laser ablation on phototherapeutic keratectomy (PTK) mode of $5 \mathrm{~mm}$ diameter zone with transition zone of up to $5.5 \mathrm{~mm}$. Further, we formed $5 \mathrm{~mm}$ wide and $16 \mathrm{~mm}$ long corneoscleral flaps of each eye. Breaking length of the fixed samples was $5 \mathrm{~mm}$ and complied with the ablation zone. To maintain experimental integrity, we compared right and left eye corneas of the same animal with an initially uniform thickness in the center. Deepithelialized cornea of the fellow eye was preliminarily saturated with $0.1 \%$ riboflavin solution. Biomechanical testing of the corneal samples was performed using Zwick/RoellBZ 2.5/TN1S tensile-testing machine. In vivo experiments were performed on 24 eyes of 12 rabbits. The animal studies were done with Chinchilla and Soviet silver rabbits aged from 3 to 4 months in two series. In the first series, we performed transepithelial photorefractive keratectomy (TransPRK) on 12 eyes of six rabbits. The surgery procedure was performed in two stages. At the first stage, PTK mode was applied in removing the epithelium, and at the second stage, we performed spherical PRK correction $-7.0 \mathrm{D}$ with $6.5 \mathrm{~mm}$ optical zone. Under these parameters, the depth of ablation of stroma in the center was $100 \mu \mathrm{m}$. In the second series, TransPRK with spherical correction $-3.5 \mathrm{D}$ and $6.5 \mathrm{~mm}$ optical zone was performed on 12 eyes of six rabbits. The ablation depth of the cornea in the center was $50 \mu \mathrm{m}$. In both series of experiments, ablation of the right eye was performed after the saturation of the stroma with $0.25 \%$ isotonic solution of riboflavin for 3 minutes, and ablation of the left eye was performed without such saturation. Aerosol saturation was performed with B.Well WN-114 mesh nebulizer. Photorefractive ablation of the corneas was performed with the excimer laser Alcon Wavelight ${ }^{\circledR}$ Allegretto 200. Optical coherence tomography (OCT) of the corneas before and after the surgery was performed using RTVue-100.

Twelve eyes of six rabbits of the first series and two eyes of one rabbit of the second series from in vivo experimental group were taken for examination by light and electron microscopy. Ten corneas of five rabbits of the second series were exposed to biomechanical strength testing 21 days after TransPRK (Figure 1). Thus, the total number of eyes undergoing biochemical test (Table 1) was 32 (16 rabbits) and ten (five rabbits) in ex vivo and in vivo experiments, respectively.

We performed corneal OCT on 36 eyes of 18 patients with varying degrees of myopia at different times after the TransPRK with preliminary saturation of the stroma with $0.25 \%$ isotonic solution of riboflavin for 3 minutes. OCT studies were conducted on Cirrus HD-OCT5000. The surgeries were performed on MEL-80 and WaveLightEX500 excimer laser systems.

\section{Results}

Both in ex vivo and in vivo studies revealed no effect of saturation of the corneal stroma with riboflavin on ablation accuracy. In respect to in vivo experiments performing $100 \mu \mathrm{m}$ depth spherical TransPRK correction -7.0 D without riboflavin saturation, initial thickness prior to ablation was $342.2 \pm 46.7 \mu \mathrm{m}$ and $244.5 \pm 41.7 \mu \mathrm{m}$ after ablation. The initial thickness of the cornea before performing the same procedure on the fellow eye with preliminary riboflavin saturation was $354 \pm 54 \mu \mathrm{m}$ and equaled $253.7 \pm 47.4 \mu \mathrm{m}$ after the procedure. There was no difference in the residual corneal thickness with and without riboflavin upon $-3.5 \mathrm{D}$ and $50 \mu \mathrm{m}$ depth ablation. This indicates no impact of saturation of the corneal stroma with riboflavin on photorefractive ablation accuracy.

As for the primary response of the TransPRK, the most visible was the difference in the group of a $100 \mu \mathrm{cm}$ central ablation depth without riboflavin saturation of the stroma. It resulted in a greater intensity of the corneal syndrome and slower epithelialization during the ablation. We associate this difference with the screening of the secondary UV-emission by riboflavin and its penetration to the deeper layers of the stroma, and also its antioxidant activity (Figure 2). In case of a $50 \mu \mathrm{cm}$ central ablation depth TransPRK, this difference 


\section{1 week after ablation}

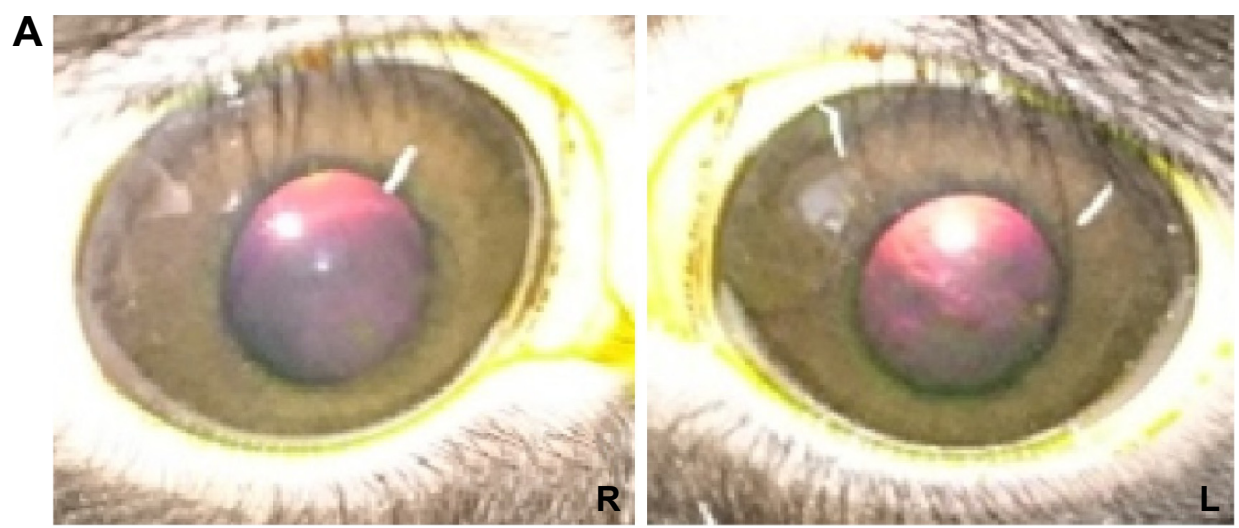

3 weeks after ablation
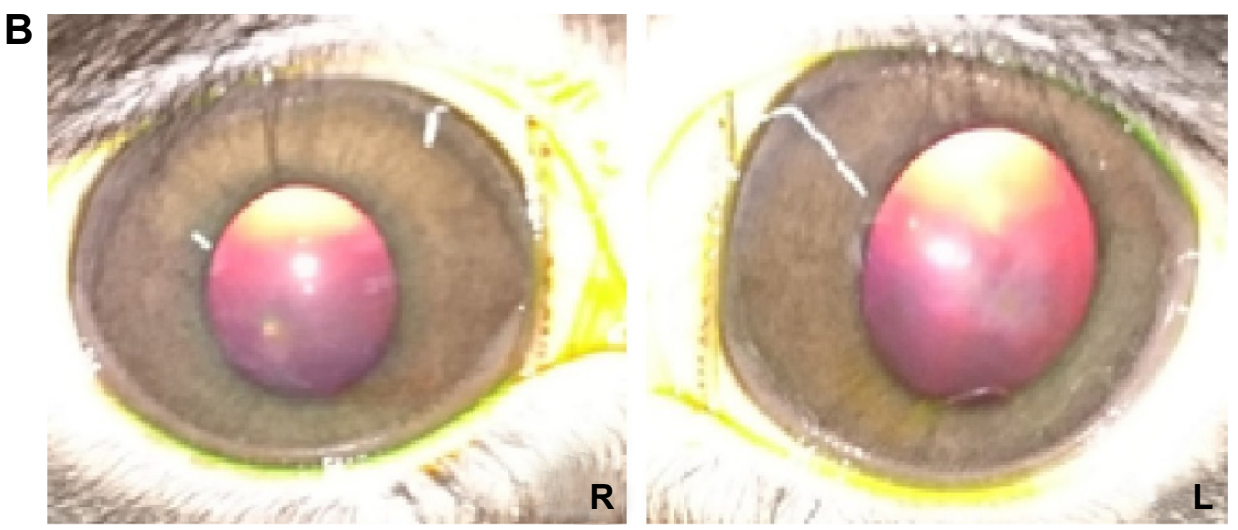

Figure I A rabbit's corneal condition I (A) and 3 (B) weeks after photorefractive ablation without $(\mathrm{L})$ and with $(\mathrm{R})$ presaturation of the stroma with riboflavin solution to a central depth of $50 \mu \mathrm{cm}$, sphere $-3.5 \mathrm{D}$.

Abbreviations: L, left; R, right.

was scarcely perceptible due to the accelerated aseptic inflammatory response. However, the final conclusions can be made from the results of morphological studies by light and electronic microscopy. Presentation of these results is beyond the scope of this paper and the data will be presented in our subsequent publications.
Both ex vivo and in vivo experiments confirmed the increase in the biomechanical properties of the corneal samples of rabbits ablated with riboflavin, as compared to those not saturated with riboflavin samples. The conclusion was based on analysis of indicators such as tensile strength and maximum strength (Table 1). Biomechanical strength testing

Table I Biomechanical properties of the corneal samples after ex vivo $100 \mu \mathrm{m}$ ablation depth PTK and in vivo $50 \mu \mathrm{m}$ ablation depth TransPRK correction of $-3.5 \mathrm{D}$ with and without preliminary saturation of the stroma with riboflavin (M $\pm S D)$

\begin{tabular}{|c|c|c|c|c|c|c|}
\hline Biomechanical & \multicolumn{2}{|c|}{ Tensile strength (MPa) } & \multicolumn{2}{|c|}{ Maximum strength (N) } & \multicolumn{2}{|c|}{$\begin{array}{l}\text { Modulus of elasticity } \\
(\mathrm{YM})\left(\mathrm{N} / \mathrm{mm}^{2}\right)\end{array}$} \\
\hline $\begin{array}{l}\text { Original corneal samples } \\
\text { (PTK, } 100 \mu \mathrm{m}, \mathrm{n}=10)\end{array}$ & $5.1 \pm 0.6$ & & $19.2 \pm 2.1$ & & $0.9 \pm 0.5$ & \\
\hline $\begin{array}{l}\text { With riboflavin saturation } \\
\text { (PTK, } 100 \mu \mathrm{m}, \mathrm{n}=\mathrm{II} \text { ) }\end{array}$ & $7.2 \pm 1.6$ & $\begin{array}{l}P=0.001 I \\
t=4.4\end{array}$ & $12.0 \pm 2.8$ & $\begin{array}{l}P=0.005 \\
t=3.08\end{array}$ & $0.9 \pm 0.4$ & $\begin{array}{l}P=0.016 \\
t=2.5\end{array}$ \\
\hline $\begin{array}{l}\text { Without riboflavin saturation } \\
\text { (PTK, } 100 \mu \mathrm{m}, \mathrm{n}=\mathrm{II} \text { ) }\end{array}$ & $5.1 \pm 1.4$ & & $8.7 \pm 2.5$ & & $0.5 \pm 0.2$ & \\
\hline $\begin{array}{l}\text { With riboflavin saturation } \\
\text { (TransPRK, } 50 \mu \mathrm{m}, \mathrm{n}=5 \text { ) }\end{array}$ & $\mid 2.8 \pm 1.3$ & $\begin{array}{l}P=0.0004 \\
t=5.7\end{array}$ & $18.3 \pm 1.2$ & $\begin{array}{l}P=0.0004 \\
t=5.9\end{array}$ & $1.0 \pm 0.3$ & $P=0.7$ \\
\hline $\begin{array}{l}\text { Without riboflavin saturation } \\
\text { (TransPRK, } 50 \mu \mathrm{m}, \mathrm{n}=5 \text { ) }\end{array}$ & $8.8 \pm 0.9$ & & $12.8 \pm 1.6$ & & $0.9 \pm 0.2$ & \\
\hline
\end{tabular}

Abbreviations: PTK, phototherapeutic keratectomy; TransPRK, transepithelial photorefractive keratectomy; M, mean; SD, standard deviation; YM, Young's modulus. 

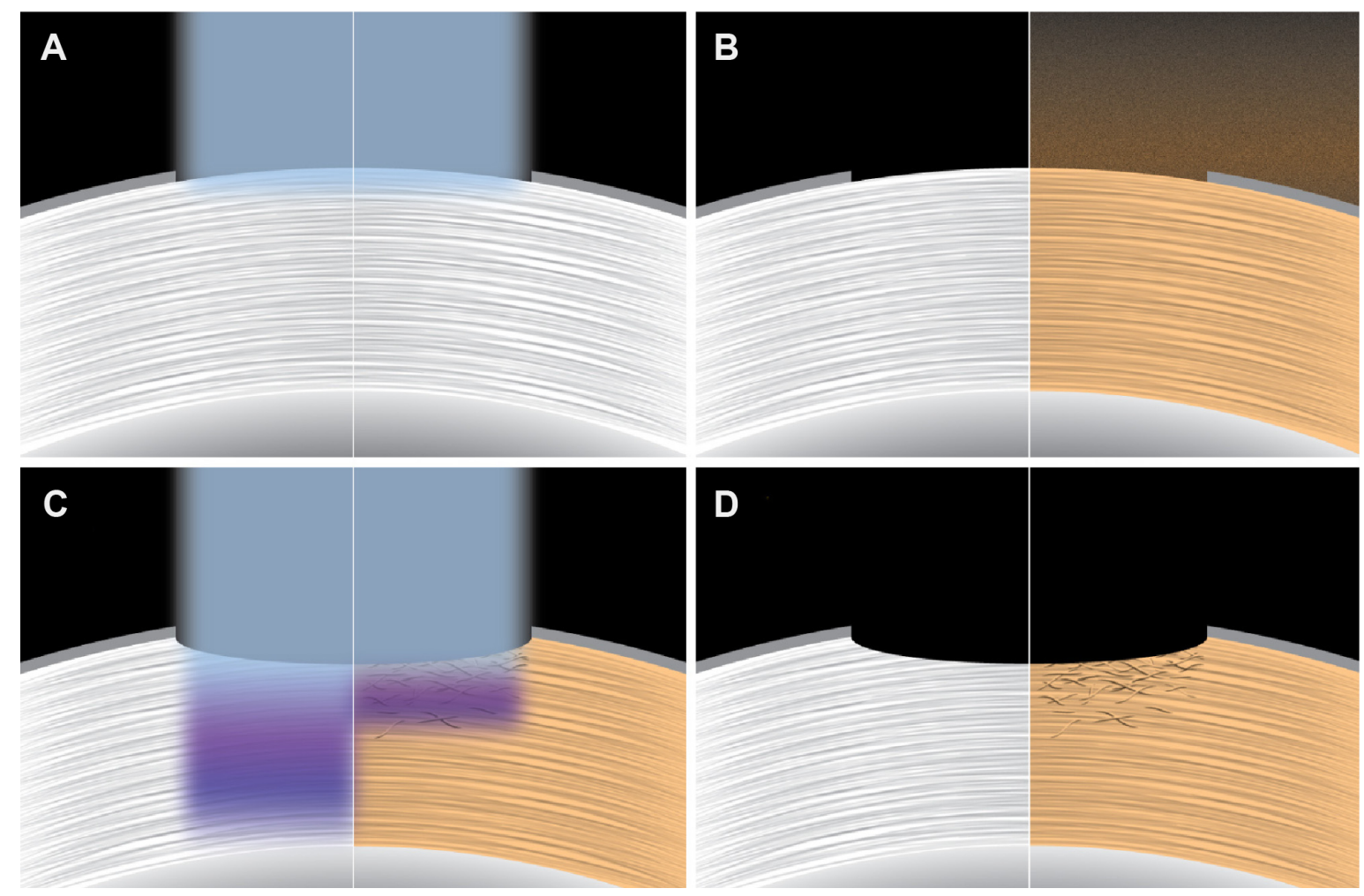

Figure 2 Schematic diagram of the TransPRK surgery without (left half) and with the effect of cross-linking (right half) when performing ablation after riboflavin saturation of the stroma.

Notes: (A) Removal of the epithelium (PTK mode); (B) saturation of the stroma with riboflavin; (C) photorefractive ablation; and (D) corneal stroma state upon completion of the ablation without (left) and with the effect of cross-linking (right).

Abbreviations: PTK, phototherapeutic keratectomy; TransPRK, transepithelial photorefractive keratectomy.

of the corneal samples following $50 \mu \mathrm{m}$ ablation depth spherical TransPRK correction $-3.5 \mathrm{D}$ with preliminary riboflavin saturation of the stroma and without saturation on a fellow eye in in vivo experiments is presented in Figure 3.

Lack of significant difference in modulus of elasticity in the in vivo experiments indicated physiologic nature of the proposed laser-induced cross-linking technology. Performing OCT imaging on rabbit corneas after ablation with riboflavin, we noted a more intense optical density in the layers of the stroma, directly adjacent to the area of excimer laser exposure. These changes were regarded as a laser modification of the ablated corneal surface due to the cross-linking effect.

Performed experimental studies formed the basis of a new technology of photorefractive surgery on the cornea, which results in saturation of the corneal stroma with riboflavin prior to performing excimer laser ablation. ${ }^{6,7}$

Schematic diagram of the TransPRK surgery without (left half) and with an effect of cross-linking (right half) when performing ablation after saturation stroma riboflavin is shown in Figure 2.

The results of this laser technology have been traced to a period of 1 month up to 2 years and are set forth in the previously published papers. ${ }^{8-10}$ In the course of OCT performed after TransPRK with riboflavin, we discovered a thin membrane-like structure beneath the epithelium and noted an increase in the optical density in the layers of the stroma adjacent to the ablation zone (Figure 4). These changes do not affect the transparency of the cornea as a whole.

\section{Discussion}

Conductance of the experimental studies was based on a need to address a number of critical issues. First of all, it concerned the possibility of applying secondary emission induced by excimer laser ablation of the stroma for the crosslinking of corneal collagen. This was due to the nature of the spectral range of secondary emission and its short interval of activity during the excimer laser ablation. The question of the influence of saturation of the corneal stroma on the photoablation accuracy was equally important. Finally, it was necessary to make sure whether the classical technique of biomechanical testing was able to detect the effect of laserinduced cross-linking.

Analyzing the available published data on the spectrum of corneal ablation, we revealed that excimer laser with an emission wavelength of $193 \mathrm{~nm}$, absorbed in the stroma, 


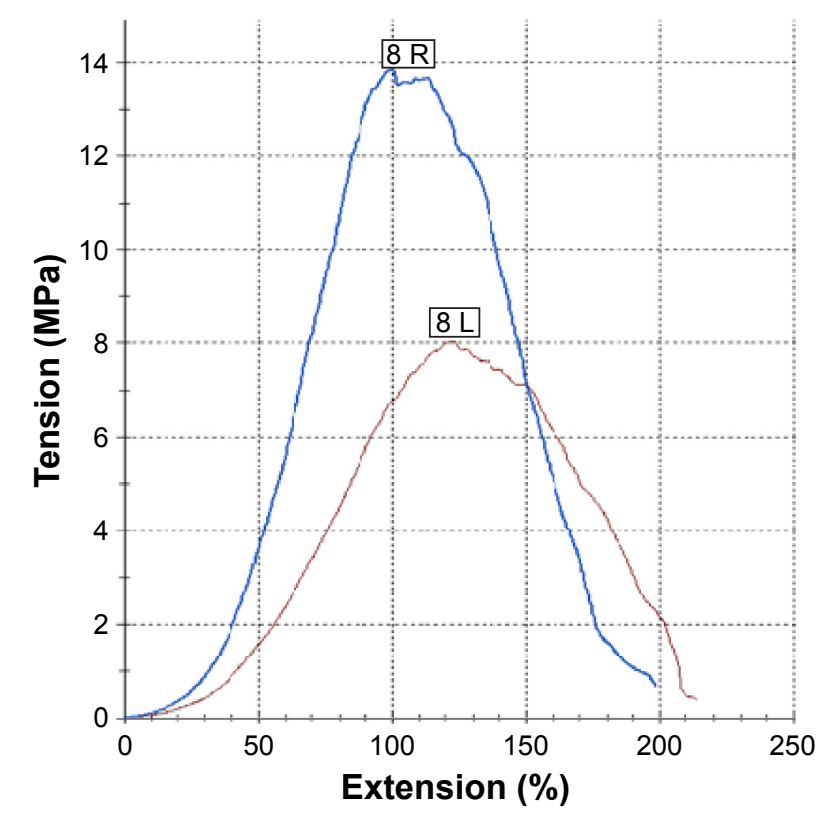

Figure 3 Biomechanical tensile strength of the rabbit corneal samples after spherical TransPRK correction $-3.5 \mathrm{D}$ (central ablation depth $50 \mu \mathrm{m}$ ) with preliminary riboflavin saturation $(R)$ and without saturation $(L)$ of the stroma on the fellow eye in in vivo experiments.

Abbreviations: TransPRK, transepithelial photorefractive keratectomy; R, right; L, left; sph, sphere.

induces secondary emission in the UV and visible range, which penetrates much deeper than the ablated tissue layer. ${ }^{11-13}$ This emission causes a cascade fluorescence of collagen stroma proteins, and its nature changes moving from the epithelium to Bowman's membrane and the stroma. These differences are most significant between the epithelium and the stroma. Analysis of the corneal ablation spectrum and riboflavin absorption spectrum revealed that ablation-induced secondary emission contains a range of wavelengths, which may cause cross-linking effect when absorbed by riboflavin in the corneal stroma. Moreover, the ablation spectrum of the epithelium, Bowman's membrane, and the stroma is different (Figure 5). ${ }^{13}$ These differences are most significant between the epithelium and the stroma. Suffice to note that the corneal

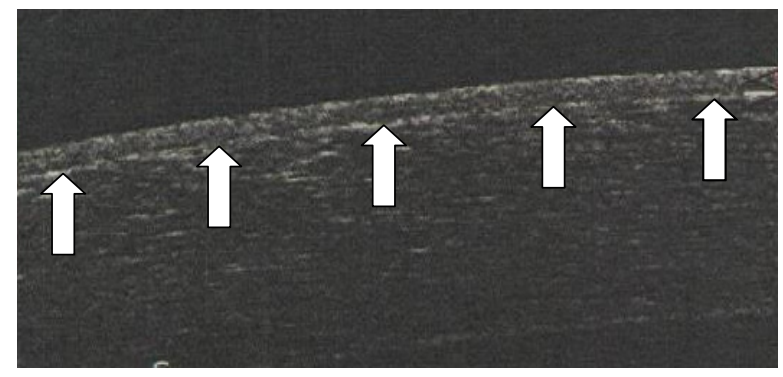

Figure 4 Membrane-like structure (arrows) of biomicroscopic transparent cornea beneath the epithelium according to OCT studies performed 1.5 years after the TransPRK with preliminary riboflavin saturation of the stroma.

Abbreviations: OCT, optical coherence tomography; TransPRK, transepithelial photorefractive keratectomy. ablation spectrum has middle (UV-B) and near (UV-A) UV radiation ranges. Moreover, the highest peak of UV-A radiation upon the ablation of the epithelium corresponds to wavelength of $270-365 \mathrm{~nm}$, which is used in clinical practice for crosslinking. However, most attention was attracted by the ability of riboflavin to absorb light in the UV range, which marked the highest value of the extinction coefficients (Figure 5). Thus, in the wavelength range from 200 to $280 \mathrm{~nm}$ (UV-C), the extinction coefficient was no less than $10,000 \mathrm{~L} \cdot \mathrm{mol}^{-1} \cdot \mathrm{cm}^{-1}$. Furthermore, another two highest peaks were observed in the same range: a wavelength of $220 \mathrm{~nm}$ with an extinction coefficient of $27,000 \mathrm{~L} \cdot \mathrm{mol}^{-1} \cdot \mathrm{cm}^{-1}$ and a wavelength of $265 \mathrm{~nm}$ with an extinction coefficient of $30,000 \mathrm{~L} \cdot \mathrm{mol}^{-1} \cdot \mathrm{cm}^{-1} \cdot{ }^{6}$ In this wavelength range of the UV radiation, total extinction coefficient is, on average, three times higher than when applying near-UV radiation spectral range. In turn, the absorption in the wavelength range from 330 to $475 \mathrm{~nm}$ has a molar extinction coefficient of no less than $5,000 \mathrm{~L} \cdot \mathrm{mol}^{-1} \cdot \mathrm{cm}^{-1}$. Within the same range, there are two peaks with an extinction coefficient of $10,000 \mathrm{~L} \cdot \mathrm{mol}^{-1} \cdot \mathrm{cm}^{-1}$ at a wavelength of 370 and $440 \mathrm{~nm}$, respectively (Figure 5). Therefore, the cross-linking effect, with the extinction coefficient sufficient to cause cross-links, may be achieved over a fairly wide range of UV wavelengths. Laser-induced secondary emissions consist of UV-B and UV-A radiation ranges that form cross-links in collagen structures of the cornea when absorbed in the riboflavin-saturated stroma (Figure 2). Moreover, due to fading of the absorption effect of the riboflavin-saturated stroma, the greatest number of cross-links will be formed directly in a thin layer adjacent to the ablation zone. ${ }^{6}$

Laser-induced cross-linking has several advantages over the method of accelerated cross-linking and its various modifications, used in photorefractive corneal surgery. ${ }^{13,14}$ This is due to the elimination of additional UV load on the

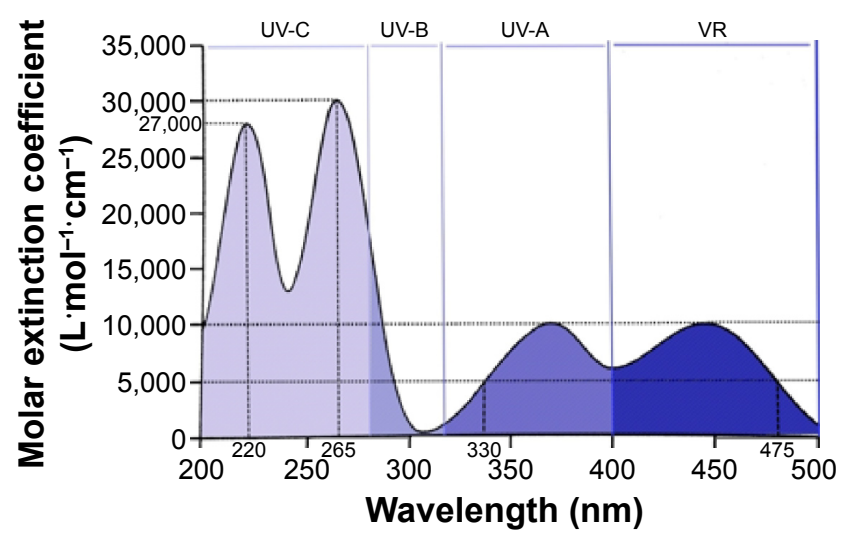

Figure $\mathbf{5}$ The absorption spectra of riboflavin have several peaks of different extinction coefficients of deep (C), middle (B), and near (A)-UV radiation ranges. Abbreviations: UV, ultraviolet; VR, visible range. 
cornea, which was already exposed to oxidative stress during photoablation.

Suffice it to mention a study by Erie et al, that revealed reduction in the density of keratocytes in all layers of the cornea during 5 years of observation after PRK and LASIK (laser-assisted in situ keratomileusis). ${ }^{15}$ This considerably explains the negative attitude of photorefractive surgeons to cross-linking, associated with the death of keratocytes to a depth of $300 \mu \mathrm{m}$ with the formation of a demarcation line. It should also be mentioned that exceeding the physiological values of corneal modulus of elasticity (Young's modulus) and increase in tensile strength by two to three times gives excessive "rigidity". The expediency of such a significant increase in strength after photorefractive surgeries needs to be clarified. This is due to possible impairment of damped role of the cornea upon accommodative-convergent intraocular pressure fluctuations, accompanied by corresponding heterotonia between the front and back parts of the eye. ${ }^{15}$ In our opinion, biomechanical properties of the cornea exposed to crosslinking should be close to these of the non-operated corneas of people of the same age. Studies have proved that laser-induced corneal cross-linking upon photorefractive ablation with riboflavin meets these requirements.

\section{Conclusion}

1. Secondary emission induced by excimer laser ablation causes cross-linking effect in the riboflavin-saturated corneal stroma.

2. According to experimental and clinical research, laserinduced cross-linking of the cornea is accompanied by increase in its tensile strength, maximum strength, and increase in the optical density in the layers of the stroma, adjacent to the keratectomy exposure.

3. A membrane-like structure, formed beneath the epithelium following the TransPRK with saturation of the stroma with riboflavin, is verified to have no effect on transparency of the cornea as a whole.

\section{Disclosure}

The authors report no conflicts of interest in this work.

\section{References}

1. Celik HU, Alagöz N, Yildirim Y, et al. Accelerated corneal crosslinking concurrent with laser in situ keratomileusis. J Cataract Refract Surg. 2012;38:1424-1431.

2. Mrochen M. Current status of accelerated corneal cross-linking. Ind J Ophthalmol. 2013;8:428-429.

3. Li N, Peng XJ, Fan ZJ. Progress of corneal collagen cross-linking combined with refractive surgery. Int J Ophthalmol. 2014;7(1):157-162.

4. Ashoori M, Saedisomeolia A. Riboflavin (vitamin B2) and oxidative stress: a review. Br J Nutr. 2014;20:1-7.

5. Kornilovskiy IM. Novye podkhody k eksimerlazernoy khirurgii rogovitsy na osnove fotoprotektsii i fotopolimerizatsii [Novel approaches to corneal excimer-laser surgery based on photoprotection and photopolymerization]. Proceedings of the International Scientific Practical Conference on Ophthalmosurgery, Ufa, Russia. 2013. East-West: 89-92. Russian.

6. Kornilovskiy IM, Burtsev AA. Teoreticheskoe i ekspiremental'noe obosnovanie lazerindutsirovannogo krosslinkinga $\mathrm{v}$ fotorefraktsionnoy khirurgii rogovitsy [Theoretical and experimental study of laser-induced crosslinking in photorefractive corneal surgery]. J Cataract Refract Surg. 2015;15(1):20-25. Russian.

7. Kornilovskiy IM, Burtsev AA, Sultanova AI, Mirishova MF, Safarova AN. The method of photorefractive keratectomy. Federal Service for Intellectual Property (Rospatent) patent RF №2014142174/14 priority 10.21.2014.

8. Kornilovskiy IM, Sultanova AI, Mirishova MF, Safarova AN. Pervye klinicheskie rezul'taty lazernoj refrakcionnoj hirurgii rogovicy s fotoprotekciej [The first clinical results of laser refractive corneal surgery with photoprotection]. J Cataract Refract Surg. 2014;14(1):21-25. Russian.

9. Kornilovskiy IM, Sultanova AI, Mirishova MF, Burtsev AA. Jeffekt fotoprotekcii i krosslinkinga pri novoj tehnologii fotorefrakcionnoj abljacii [Effects of photoprotection and cross-linking using a new technology of photorefractive ablation. Actual technologies in ophthalmology]. Res Pract. 2014;vyp.3:161-163. Russian.

10. Kornilovskiy IM, Sultanova AI, Butsev AA, Mirishova MF, Safarova AN. Transjepitelial'naja FRK s jeffektom fotoprotekcii i krosslinkinga [Transepithelial PRK with photoprotection and crosslinking effect]. J Cataract Refract Surg. 2015;15(3):27-33. Russian.

11. Tuft S, Al-Dhahir R, Dyer P, Zahao Z. Characterization of fluorescence spectra produced by excimer laser irradiation of cornea. Invest Ophthalmol Vis Sci. 1989;31:1512-1518.

12. Philips AF, McDonell PG. Laser-induced fluorescent during photorefractive keratectomy: a method for controlling epithelial removal. $\mathrm{Am}$ J Ophthalmol. 1997;123(1):42-47.

13. Cohen D, Chuk R, Berman G, McDonell, Grundfest W. Ablation spectra of the human cornea. J Biomed Opt. 2001;6(3):339-343.

14. Tomás-Juana J, Larrañagab AM, Ludger Hannekena L. Corneal Regeneration After Photorefractive Keratectomy: A Review.J Optom. 2015;8(3): 149-169.

15. Erie JC, McLaren JW, Hodge DO, Bourne WM. Long-term corneal keratocyte deficits after photorefractive keratectomy and laser in situ keratomileusis. Trans Am Ophthalmol Soc. 2015;103:56-68.
Clinical Ophthalmology

\section{Publish your work in this journal}

Clinical Ophthalmology is an international, peer-reviewed journal covering all subspecialties within ophthalmology. Key topics include: Optometry; Visual science; Pharmacology and drug therapy in eye diseases; Basic Sciences; Primary and Secondary eye care; Patient Safety and Quality of Care Improvements. This journal is indexed on Submit your manuscript here: http://www.dovepress.com/clinical-ophthalmology-journal

\section{Dovepress}

PubMed Central and CAS, and is the official journal of The Society of Clinical Ophthalmology (SCO). The manuscript management system is completely online and includes a very quick and fair peer-review system, which is all easy to use. Visit http://www.dovepress.com/ testimonials.php to read real quotes from published authors. 